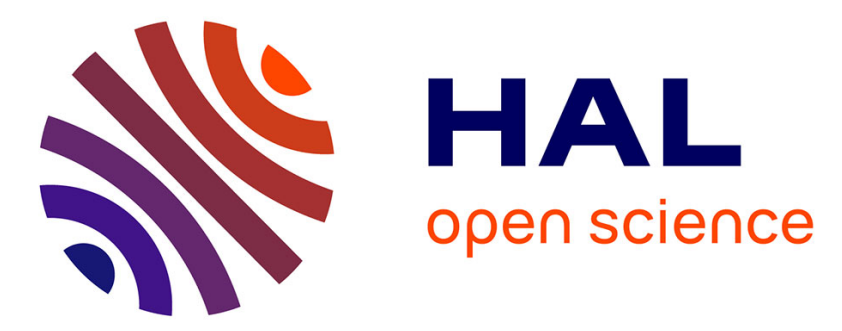

\title{
Chemiluminescence based operating point control of domestic gas boilers with variable natural gas composition
}

Yi Ding, D. Durox, Nasser Darabiha, Thierry Schuller

\section{- To cite this version:}

Yi Ding, D. Durox, Nasser Darabiha, Thierry Schuller. Chemiluminescence based operating point control of domestic gas boilers with variable natural gas composition. Applied Thermal Engineering, 2019, 149, pp.1052-1060. 10.1016/j.applthermaleng.2018.12.106 . hal-02001975

\section{HAL Id: hal-02001975 \\ https://hal.science/hal-02001975}

Submitted on 31 Jan 2019

HAL is a multi-disciplinary open access archive for the deposit and dissemination of scientific research documents, whether they are published or not. The documents may come from teaching and research institutions in France or abroad, or from public or private research centers.
L'archive ouverte pluridisciplinaire HAL, est destinée au dépôt et à la diffusion de documents scientifiques de niveau recherche, publiés ou non, émanant des établissements d'enseignement et de recherche français ou étrangers, des laboratoires publics ou privés. 


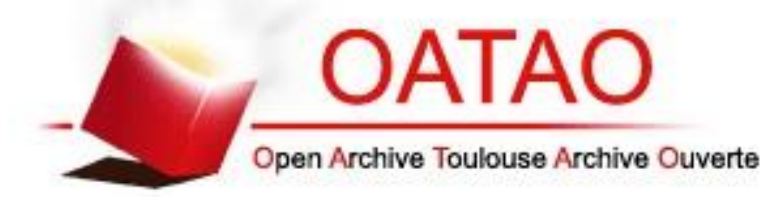

Open Archive Toulouse Archive Ouverte

OATAO is an open access repository that collects the work of Toulouse researchers and makes it freely available over the web where possible

This is an author's version published in: http://oatao.univ-toulouse.fr/21452

\section{Official URL:}

https://doi.org/10.1016/j.applthermaleng.2018.12.106

\section{To cite this version:}

Ding, Yi and Durox, Daniel and Darabiha, Nasser and Schuller, Thierry Chemiluminescence based operating point control of domestic gas boilers with variable natural gas composition. (2019) Applied Thermal Engineering, 149. 10521060. ISSN 1359-4311

Any correspondence concerning this service should be sent to the repository administrator: tech-oatao@listes-diff.inp-toulouse.fr 


\title{
Chemiluminescence based operating point control of domestic gas boilers with variable natural gas composition
}

\author{
Yi Ding ${ }^{\mathrm{a}, \mathrm{b}, *}$, Daniel Durox ${ }^{\mathrm{a}}$, Nasser Darabiha ${ }^{\mathrm{a}}$, Thierry Schuller ${ }^{\mathrm{a}, \mathrm{c}}$ \\ ${ }^{a}$ Laboratoire EM2C, CNRS, CentraleSupélec, Université Paris Saclay, 3 rue Joliot Curie, 91192 Gif-sur-Yvette, France \\ ${ }^{\mathrm{b}}$ Bosch Thermotechnologie, 126 rue de Stalingrad, 93700 Drancy, France \\ ${ }^{\mathrm{c}}$ Institut de Mécanique des Fluides de Toulouse, IMFT, Université de Toulouse, CNRS, 2 Allée du Professeur Camille Soula, 31400 Toulouse, France
}

\section{H I G H L I G H T S}

- Equivalence ratio control of domestic gas boilers using chemiluminescence signal.

- Demonstrative equivalence ratio control loop using $\mathrm{OH}^{*}$ signal and air flow rate.

- Regulation strategy validated with different natural gas compositions.

A R T I C L E I N F O

\section{Keywords:}

Domestic gas boiler

Flame chemiluminescence

Equivalence ratio regulation

Biogas

Hydrogen

\begin{abstract}
A B S T R A C T
The current control strategy of domestic gas boilers optimizes the heating efficiency and pollutant gas emissions assuming a fixed fuel composition. However, larger and more frequent variations of gas composition are expected in the European natural gas network. New control systems capable of monitoring and regulating the flame equivalence ratio in real time are therefore necessary. The present work investigates one equivalence ratio sensing strategy by analyzing the flame chemiluminescence signal from a laminar premixed burner widely used in domestic gas boilers. The $\mathrm{OH}^{*}$ chemiluminescence intensity is first identified as a reliable equivalence ratio indicator, valid for different natural gas composition scenarios with $\mathrm{CH}_{4}$ diluted by $\mathrm{N}_{2}$ or $\mathrm{CO}_{2}$ or enriched by $\mathrm{H}_{2}$, $\mathrm{C}_{2} \mathrm{H}_{6}$ or $\mathrm{C}_{3} \mathrm{H}_{8}$. These fuel mixtures are representative of biogas and hydrogen enriched natural gas. A demonstrative control loop is developed based on the $\mathrm{OH}^{*}$ signal measured by a photomultiplier tube mounted with a bandpass optical filter. The system is tested by changing the equivalence ratio set value and the fuel composition. It is shown to be capable of regulating the equivalence ratio of these natural gas fuel blends with a good precision. The differences observed between the real and target values for the equivalence ratio $\phi$ are in most cases lower than $|\Delta \phi|=0.01$. Only fuel blends with $\mathrm{C}_{3} \mathrm{H}_{8}$ lead to slightly larger errors of $|\Delta \phi|=0.03$.
\end{abstract}

\section{Introduction}

The European natural gas network is expecting larger and more frequent variations of the gas composition in the future. This evolution results first from a more diversified set of supply sources due to the liberalization of the gas market. It results also from the growing integration in the network of gases from renewable resources as biogas and hydrogen [1,2]. These evolutions set a challenge for domestic gas boiler manufacturers, who must ensure optimized performances of their apparatus despite the composition variations of gas supply.

Fully premixed burners are widely used in modern household gas boilers $[3,4]$. To maximize the heat efficiency and reduce CO and NOx emissions, it is important to control the combustible mixture equivalence ratio at all operating conditions including the transient states. Insufficient excess air leads to high $\mathrm{CO}$ emissions due to incomplete combustion and high flame temperatures also promote NOx production [5]. On the other hand, too much excess air causes flame detachment, prone to CO production as well, and the heat efficiency is also compromised due to higher heat losses in the flue gases [6]. A compromise is therefore sought and the equivalence ratio should be maintained within an optimized range [4]. The current boiler control strategy assumes a fixed natural gas composition but this paradigm is not valid anymore. An automatic combustion control system is necessary to regulate the operating point according to the changes of the fuel blend composition. For this purpose, the first challenge is to detect the equivalence ratio in real time with low cost sensors.

\footnotetext{
* Corresponding author at: Laboratoire EM2C, CNRS, CentraleSupélec, Université Paris Saclay, 3 rue Joliot Curie, 91192 Gif-sur-Yvette, France.

E-mail address: yi.ding7@fr.bosch.com (Y. Ding).
} 
Reviews on potential sensor technologies for the equivalence ratio detection have been carried by Docquier and Candel [7] and by Tschulena and Lahrmann [8]. Current regulation systems emerging on the market are generally based on sensing the flame ionization current $[9,10]$, thanks to the simplicity of this technique. However, the ionization current intensity is sensitive to the fuel composition, which may cause errors for detecting the equivalence ratio. These errors may have two origins. First, variations of the fuel composition modify the laminar burning velocity and hence the flame standoff distance with respect to the burner outlet [11], which largely decides the ionization current intensity [12-14]. The magnitude of the resulting error on the equivalence ratio has been characterized in a previous work [12]. Secondly, when the ionization probe is set downstream the flame front in the burnt gases region, the ionization current intensity becomes very sensitive to the flame-probe distance, which may vary with different gas compositions.

The present work explores an alternative solution to control the equivalence ratio of methane blends with a secondary component by analyzing the flame chemiluminescence signal. This signal is well known to be sensitive to the equivalence ratio and is also easy to measure [15-18]. Techniques based on sensing the chemiluminescence signal from flames to monitor the equivalence ratio of industrial burners have been reviewed by Ballester and García-Armingol [18]. These techniques have also been recently envisaged to control gasification processes by relating the chemiluminescence signal with the oxygen to carbon ratio $[19,20]$.

A commonly used equivalence ratio indicator for lean hydrocarbon fuel/air flames is the $\mathrm{CH}^{*} / \mathrm{OH}^{*}$ intensity ratio [21]. This signal has the advantage to barely depend on flame power and strain rate [22-25]. Docquier et al. [26] developed a laboratory demonstrative equivalence ratio controller for a conical methane-air flame based on a lookup table consisting of two intensity ratios $\mathrm{OH}^{*} / \mathrm{CH}^{*}$ and $\mathrm{CO}_{2}^{*} / \mathrm{CH}^{*}$. This control strategy was tested with success to adjust the equivalence ratio to the set value for methane/air mixtures and also when the fuel is diluted with $\mathrm{N}_{2}$. However, it has recently been shown that, although the $\mathrm{CH}^{*} / \mathrm{OH}^{*}$ intensity ratio remains a reliable indicator of the equivalence ratio for $\mathrm{N}_{2}$ and $\mathrm{CO}_{2}$ diluted methane mixtures, considerable errors are introduced for $\mathrm{C}_{2} \mathrm{H}_{6}$ and $\mathrm{C}_{3} \mathrm{H}_{8}$ enriched methane blends even with relatively low volumetric fractions of these secondary components [12]. These two latter components are common in natural gases [27] and their impact on equivalence ratio sensing needs to be considered. An alternative indicator valid for all possible natural gas compositions needs therefore to be identified.

The present work aims at demonstrating the feasibility of equivalence ratio regulation by real time analysis of the chemiluminescence signal for a laminar premixed burner widely used in domestic gas boilers. A new equivalence ratio sensing strategy is first developed using the $\mathrm{OH}^{*}$ intensity and additional information on the air flow rate. This strategy validated for pure methane/air mixtures is then tested by adding different concentrations of $\mathrm{N}_{2}, \mathrm{CO}_{2}, \mathrm{H}_{2}, \mathrm{C}_{2} \mathrm{H}_{6}$ and $\mathrm{C}_{3} \mathrm{H}_{8}$ to the pure $\mathrm{CH}_{4}$. The transient response of the $\mathrm{OH}^{*}$ signal following a cold start of the burner is also investigated. These tests are then used to develop a control loop of the equivalence ratio with a LabVIEW program. The demonstrative control loop is finally tested by changing the equivalence ratio set value and also the fuel composition and examining the performances of the regulation system.

\section{Experimental setup}

\subsection{Burner}

Experiments are performed on the cylindrical multi-perforated burner shown in Fig. 1 widely used in modern household gas boilers and operating with fully premixed combustible mixtures. It is made of stainless steel designed to resist high flame temperatures. The surface of the burner consists of hundreds of tiny circular holes $(\varnothing=0.8 \mathrm{~mm})$ and rectangular slits $(4 \mathrm{~mm} \times 0.5 \mathrm{~mm})$. The operational power of this burner covers a range of 3 to $14 \mathrm{~kW}$ or 3 to $30 \mathrm{~kW}$ when the burner is equipped with slightly different internal flow guiding structures. The

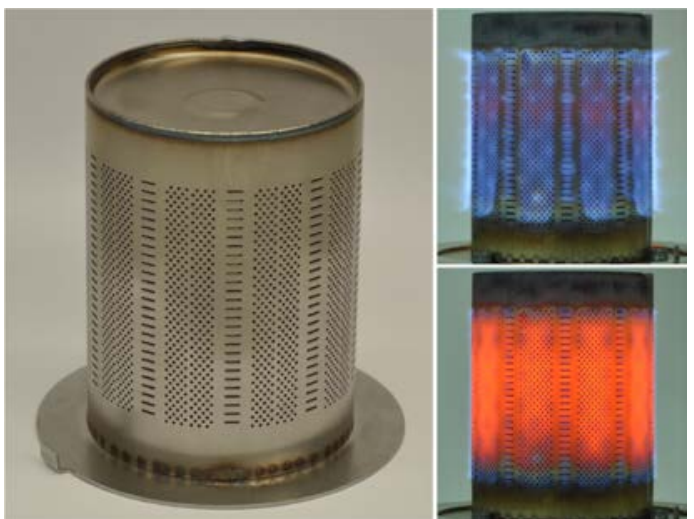

Fig. 1. Photos of the fully premixed cylindrical multi-perforated burner (left), working under regular mode (upper right) and radiation mode (lower right).

large power modulation range of this type of burner allows to meet the needs of varying heating power demand without frequent ON/OFF cycles that compromise the global energy efficiency of the system. At high power, small blue flames are stabilized above the burner surface and the operational mode is designated as "regular" as illustrated in Fig. 1 (upper right). In this regime, the thermal power is essentially transmitted to the load by convection. At low power, the flames are stabilized close to burner surface with significant heat transfer to the metallic burner components. In this case, the heat is transferred to the heat exchanger through thermal radiation of the hot burner components as well and the burner works under the so-called "radiation mode" as in Fig. 1 (lower right).

\subsection{Chemiluminescence intensity measurement}

Fig. 2 shows a schematic of the experimental setup for the chemiluminescence signal characterization. The flame light emission is recorded in two ways. For the analysis conducted in Section 3 aiming at identifying an equivalence ratio indicator, a spectral decomposition of the light detected over $200-900 \mathrm{~nm}$ is made with an OceanOptics USB2000 + spectrometer. This device is represented on the left side in Fig. 2. The optical signal is collected by a lens ( $F=10 \mathrm{~mm}, \varnothing=3 \mathrm{~mm})$ set at a distance of about $30 \mathrm{~cm}$ away from the burner surface. The field of view integrates therefore a representative circular interrogation area of about $\varnothing=30 \mathrm{~mm}$ on the burner surface.

A typical spectrum gathered from the burner is shown in Fig. 3. In addition to the chemiluminescence emissions of $\mathrm{OH}^{*}, \mathrm{CH}^{*}, \mathrm{C}_{2}^{*}$ and $\mathrm{CO}_{2}^{*}$ radicals, a strong continuous spectrum associated to the blackbody radiation is visible above $500 \mathrm{~nm}$ when the burner operates under the radiation mode. The detected spectrum $I^{\prime}(\lambda)$ is the real spectrum $I(\lambda)$ emitted by the flame filtered by the device response function: $I^{\prime}(\lambda)=I(\lambda) R(\lambda)$. Correction for the apparatus response function $R(\lambda)$ is not performed in this study, since only evolutions of the emission intensities rather than their absolute values are of interest in the present study. The chemiluminescence intensities of $\mathrm{OH}^{*}, \mathrm{CH}^{*}$ and $\mathrm{C}_{2}^{*}$ are determined by measuring the height of the emission peaks with respect to the baseline emission background [28]. Indeed, the interpretation of the

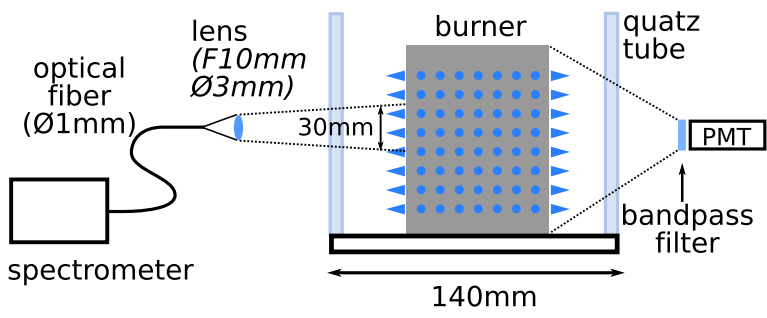

Fig. 2. Chemiluminescence signal characterization. 


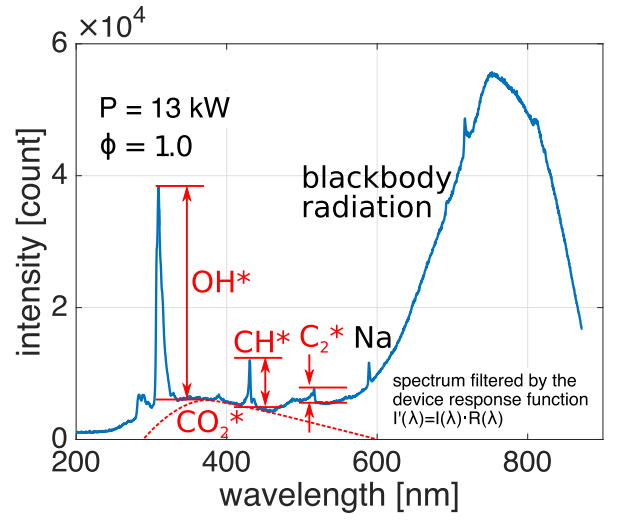

Fig. 3. Typical spectrum of a methane-air flame stabilized on the cylindrical multi-perforated burner. $P=13 \mathrm{~kW}, \phi=1.0$.

chemiluminescence intensity by taking the peak height or the peak area makes no significant difference as the shapes of the peaks are generally self-similar [29]. The broadband emission of $\mathrm{CO}_{2}^{*}$ is often represented by its value at $450 \mathrm{~nm}$ [30]. However, invasion of the blackbody radiation is probable at this wavelength when the burner operates under the radiation mode. An alternative choice is to infer the $\mathrm{CO}_{2}^{*}$ signal at a slightly shorter wavelength of $370 \mathrm{~nm}$ to avoid any interference with the thermal radiation of the hot metallic components of the burner.

The chemiluminescence intensity is also determined, as represented on the right side in Fig. 2, with a photomultiplier tube (Hamamatsu H11902-110) mounted with a bandpass optical filter centered at the corresponding wavelength, set at about $50 \mathrm{~cm}$ from the burner. Measurements with this second technique are easier and faster. They are used in Section 4 for the equivalence ratio control loop. The field of view is large in this case and includes the whole burner. However, all the light emission originating from the different radicals within the filter passband is integrated, without the possibility of removing the continuous baseline attributed essentially to the $\mathrm{CO}_{2}^{*}$ emission and thermal radiation from the hot metallic components. This is acceptable to detect the $\mathrm{OH}^{*}$ contribution as its intensity is dominant in the corresponding range of wavelengths from 300 to $325 \mathrm{~nm}$. However, the weaker peak emissions of $\mathrm{CH}^{*}$ around $431 \mathrm{~nm}$ and $\mathrm{C}_{2}^{*}$ around $516 \mathrm{~nm}$ cannot be measured reliably in this way.

\section{Equivalence ratio sensing}

\subsection{Indicator for equivalence ratio}

The aim of the present work is to monitor and automatically regulate the equivalence ratio by analyzing the flame chemiluminescence signal when the natural gas composition varies. A reliable indicator for the equivalence ratio is required for this purpose. The indicator should be sensitive to changes of equivalence ratio, but insensitive to the fuel composition. Ideally it is also desirable to be independent of flame power. Possible indicators are tested with pure methane and binary fuel blends composed of methane and one of the secondary components including $\mathrm{N}_{2}, \mathrm{CO}_{2}, \mathrm{H}_{2}, \mathrm{C}_{2} \mathrm{H}_{6}$ and $\mathrm{C}_{3} \mathrm{H}_{8}$. The volumetric fractions of secondary components in the fuel blends are selected as follows: $X^{\text {fuel }}\left(\mathrm{N}_{2}\right)=10 \%, X^{\text {fuel }}\left(\mathrm{CO}_{2}\right)=10 \%, X^{\text {fuel }}\left(\mathrm{H}_{2}\right)=20 \%, X^{\text {fuel }}\left(\mathrm{C}_{2} \mathrm{H}_{6}\right)=10 \%, X^{\text {fuel }}\left(\mathrm{C}_{3} \mathrm{H}_{8}\right)=5 \%$. In these expressions, $X^{\text {fuel }}(Y)$ stands for the volumetric fraction of the secondary component $Y$ with respect to the methane and secondary component blend: $X^{\text {fuel }}(Y)=X_{Y} /\left(X_{\mathrm{CH}_{4}}+X_{Y}\right)$. They are chosen to represent the maximum values expected in future natural gas blends in EU by also considering the injection of biogas and hydrogen [27,31].

Three indicators including the $\mathrm{CH}^{*} / \mathrm{OH}^{*}$ and $\mathrm{C}_{2}^{*} / \mathrm{CH}^{*}$ intensity ratios and the $\mathrm{OH}^{*}$ intensity are plotted as a function of the equivalence ratio in Fig. 4 for different fuel compositions and a fixed power of $P=13 \mathrm{~kW}$.

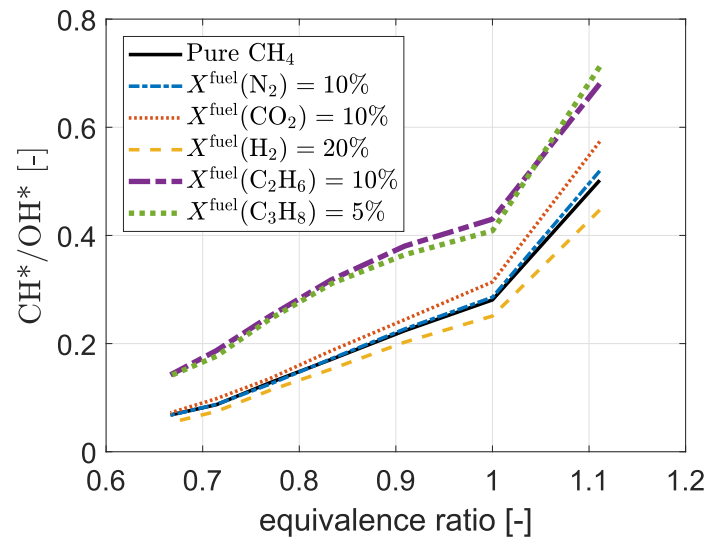

(a) $\mathrm{CH}^{*} / \mathrm{OH}^{*}$ vs. equivalence ratio

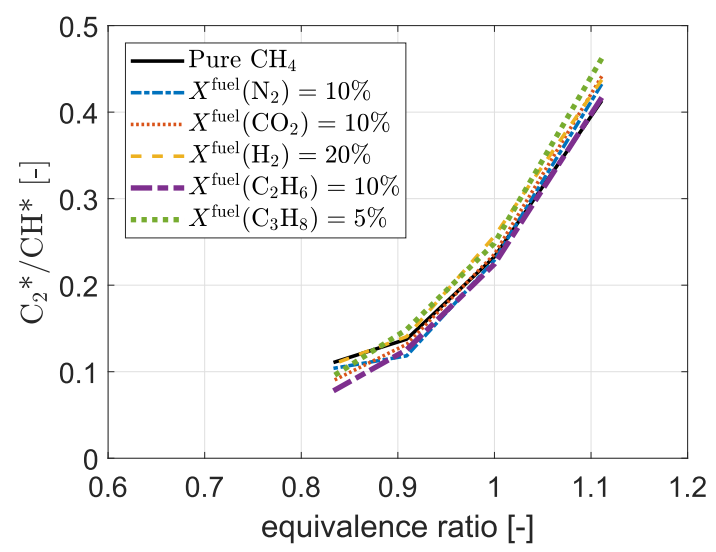

(b) $\mathrm{C}_{2}^{*} / \mathrm{CH}^{*}$ vs. equivalence ratio

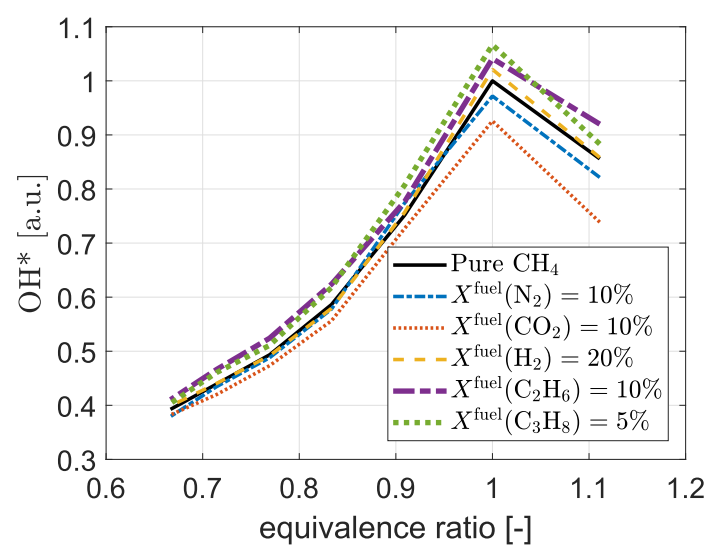

(c) $\mathrm{OH}^{*}$ vs. equivalence ratio

Fig. 4. Evolutions of $\mathrm{CH}^{*} / \mathrm{OH}^{*}, \mathrm{C}_{2}^{*} / \mathrm{CH}^{*}$ intensity ratios and $\mathrm{OH}^{*}$ intensity as a function of equivalence ratio for different fuel compositions and a fixed power $P=13 \mathrm{~kW}$

The intensity ratio $\mathrm{CH}^{*} / \mathrm{OH}^{*}$ is commonly used to deduce the equivalence ratio in many premixed systems powered by methane/air flames. However, Fig. $4 \mathrm{a}$ reveals that addition of $\mathrm{C}_{2} \mathrm{H}_{6}$ and $\mathrm{C}_{3} \mathrm{H}_{8}$ leads to a considerable drift of the response with respect to the reference case with pure $\mathrm{CH}_{4}$. The resulting bias error $|\Delta \phi|>0.1$ between the predicted and real values for the equivalence ratio $\phi$ of the fuel mixture with these secondary component concentrations is too big for the targeted application of flame monitoring. The same conclusion was reached in [12] for a conical flame. The $\mathrm{CH}^{*} / \mathrm{OH}^{*}$ intensity ratio is therefore not a reliable and robust indicator for methane blends with heavier hydrocarbon components. 
In Fig. $4 \mathrm{~b}$, the $\mathrm{C}_{2}^{*} / \mathrm{CH}^{*}$ intensity ratio is used as an alternative indicator. Injection of secondary components cause very small drifts of the $\mathrm{C}_{2}^{*} / \mathrm{CH}^{*}$ signal. Differences between the real and predicted equivalence ratios remain lower than $|\Delta \phi|=0.03$. However, the $C_{2}^{*}$ emission intensity remains weak for methane-air flames and is hardly detectable at lean conditions for $\phi \lesssim 0.8$. The operable range of the $\mathrm{C}_{2}^{*} / \mathrm{CH}^{*}$ intensity ratio available to safely recover the equivalence ratio in Fig. $4 \mathrm{~b}$ is insufficient for domestic gas boilers operating around $\phi=0.8$. Nevertheless, the curves in Fig. $4 \mathrm{~b}$ are monotonic over the range $0.83 \leqslant \phi \leqslant 1.11$ and this indicator exhibits excellent robust properties with respect to fuel composition variations. It then has the potential to be used to control combustion apparatus operating closer to stoichiometry, or used in combination with another indicator more suitable to leaner operating conditions.

A simpler alternative is envisaged in Fig. $4 \mathrm{c}$ by examining the $\mathrm{OH}^{*}$ intensity alone. The response of the $\mathrm{OH}^{*}$ intensity as the equivalence ratio changes is barely altered by the injection of all secondary components tested and the bias error on the detected equivalence ratio remains limited within $|\Delta \phi|<0.03$. Also, the response is monotonic over $0.67 \leqslant \phi \leqslant 1.00$, a dynamical range which is large enough and covers that of many gas boiler burners. One may however note a different trend beyond stoichiometry.

The $\mathrm{OH}^{*}$ intensity signal is therefore an appropriate equivalence ratio indicator for the targeted application of flame monitoring in a domestic gas boiler. Nevertheless, as only one emission intensity is used, the impact of flame power needs to be considered as well. This issue is addressed below in Section 3.2.

\subsection{Equivalence ratio sensing with $\mathrm{OH}^{*}$ signal}

The previous experiments led to the conclusion that the $\mathrm{OH}^{*}$ intensity signal is a reliable equivalence ratio indicator, with very limited impact of the fuel composition. In addition, from the viewpoint of application to real gas boilers, this strategy also offers several important advantages:

- The $\mathrm{OH}^{*}$ intensity can be measured reliably with a photomultiplier tube equipped with a narrow bandpass filter, without the need of subtracting the $\mathrm{CO}_{2}^{*}$ background emission intensity. This record technique has the advantage of being easier, faster and less expensive than using a spectrometer.

- The simplicity of the technique based on a unique signal intensity without various correction procedures makes it promising to be realized with low cost alternative sensors. Use of UV light sensing photodiodes might for example lead to further cost cutting.

- The fact that the $\mathrm{OH}^{*}$ intensity lies in the UV range makes it insensitive to the impact of indoor lighting and also insensitive to thermal radiation from the hot solid surfaces of the burner with light emission covering the visible and IR bands, even though the sunlight radiation might still need to be considered.

Despite these advantages, one difficulty is that the $\mathrm{OH}^{*}$ intensity directly depends on the flame thermal power. In addition, previous studies have highlighted that for the cylindrical multi-perforated burner used in the present study, the chemiluminescence intensity does not evolve linearly with the flame power over all the operating range of the burner [29]. The $\mathrm{OH}^{*}$ specific intensity corresponding to the chemiluminescence intensity normalized by the flame power in Fig. 5 does not remain constant at low power or close to stoichiometric operating conditions. Sensing the equivalence ratio based on the $\mathrm{OH}^{*}$ emission intensity can therefore not be envisaged with a single calibration curve. In a gas boiler, the flame power is not readily known and can only be determined from the natural gas flow rate and its composition. However, this missing information on the power can substituted by the air flow rate, which can be easily deduced from the air fan speed.

A sensing strategy relying on a series of calibration curves for different air flow rates is here developped. For each air flow rate, the $\mathrm{OH}^{*}$ intensity alone is used as an indicator of the equivalence ratio of the

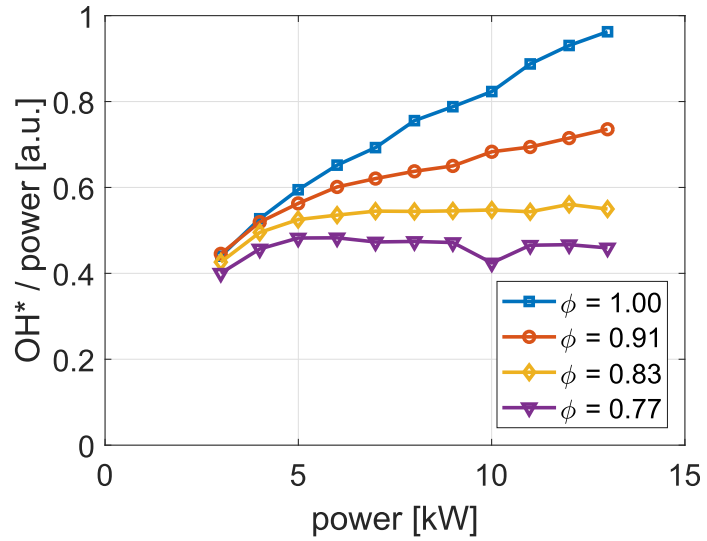

Fig. 5. $\mathrm{OH}^{*}$ specific intensity vs. power. $\mathrm{CH}_{4}$-air flames at different equivalence ratios $\phi$.

combustible mixture. The equivalence ratio can therefore be determined during operation by measuring the $\mathrm{OH}^{*}$ intensity, the air flow rate being deduced from the air fan speed.

Calibration curves of the $\mathrm{OH}^{*}$ intensity vs. equivalence ratio are first recorded for methane/air mixtures at fixed air flow rates. Fig. 6 gathers data for six equivalence ratios and seven air flow rates. Measurements are carried out only when the $\mathrm{OH}^{*}$ signal intensity has reached steady state conditions, considering the time necessary for the signal to stabilize following a cold start of the burner or a sudden change of the flow operating conditions. Results for different operating conditions are discussed below in Section 3.3. This set of curves is then transformed into a 3-D calibration surface in Fig. 7 by interpolation of the data. For the burner in operation powered by an unknown fuel blend mixture, the equivalence ratio of the combustible mixture is deduced by interpolation of the data gathered for the air flowrate and the $\mathrm{OH}^{*}$ intensity on the 3-D calibration surface built for pure methane.

\subsection{Uncertainty analysis}

\subsubsection{Impact of fuel composition}

The performance of the equivalence ratio sensing strategy is investigated for the different fuel compositions listed in the first column of Table 1. Four equivalence ratios $\phi=0.67,0.74,0.83,0.95$ are considered for each scenario. The investigated secondary components include $\mathrm{N}_{2}, \mathrm{CO}_{2}, \mathrm{H}_{2}$ and $\mathrm{C}_{3} \mathrm{H}_{8}$. The impact of $\mathrm{C}_{2} \mathrm{H}_{6}$ enrichment can be deduced from the results for $\mathrm{C}_{3} \mathrm{H}_{8}$ enrichment and is not repeated. A scenario with unpurified biogas is also considered with $50 \mathrm{vol} . \% \mathrm{CO}_{2}$ in the fuel blend.

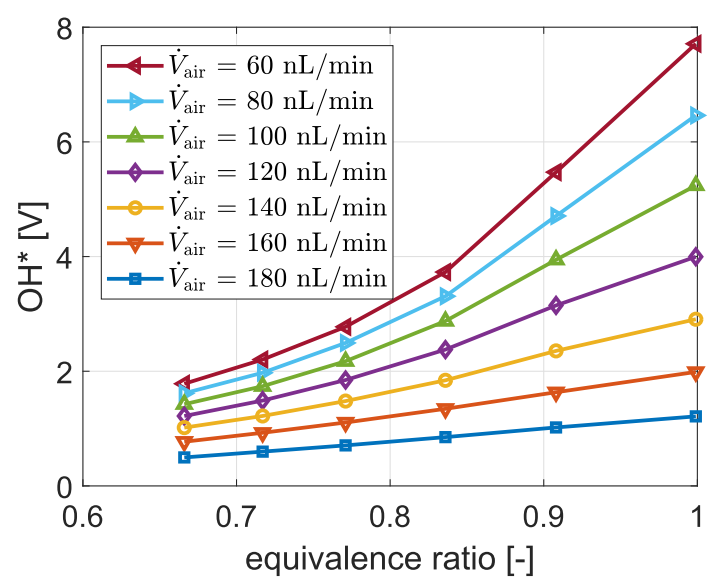

Fig. 6. Calibration curves of $\mathrm{OH}^{*}$ intensity vs. equivalence ratio for different air flow rates $\dot{V}_{\text {air }} . \mathrm{OH}^{*}$ intensities are measured by a photomultiplier tube mounted with a bandpass filter centered at $310 \mathrm{~nm}$. $\mathrm{CH}_{4}$-air mixture. 


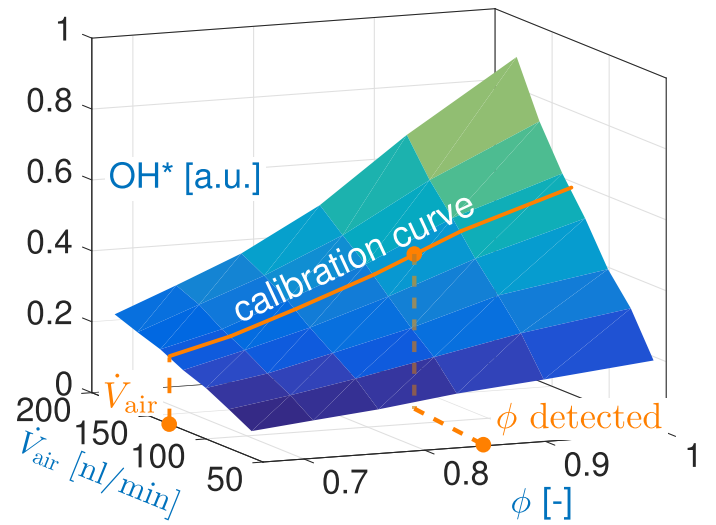

Fig. 7. Equivalence ratio sensing with the $\mathrm{OH}^{*}$ intensity. $\mathrm{CH}_{4}$-air mixture.

\section{Table 1}

Tests of the equivalence ratio sensing strategy based on $\mathrm{OH}^{*}$ emission records. $\phi$ denotes the equivalence ratio of the combustible mixture deduced from the gas flow rates injected in the system. $\phi^{\prime}$ is the equivalence ratio deduced from the sensing strategy. $\Delta \phi=\phi^{\prime}-\phi$ denotes the bias error between the real and detected equivalence ratios. The power is fixed at $P=7 \mathrm{~kW}$.

\begin{tabular}{|c|c|c|c|}
\hline Fuel & $\phi$ & $\Delta \phi \times 10^{3}$ & $\frac{\Delta \phi}{\phi} \times 100 \%$ \\
\hline \multirow[t]{4}{*}{ Pure $\mathrm{CH}_{4}$} & 0.952 & 6 & $0.6 \%$ \\
\hline & 0.833 & 3 & $0.4 \%$ \\
\hline & 0.740 & 6 & $0.8 \%$ \\
\hline & 0.666 & -7 & $-1.1 \%$ \\
\hline $\mathrm{CH}_{4} / \mathrm{N}_{2}$ & 0.952 & 8 & $0.9 \%$ \\
\hline \multirow[t]{3}{*}{$X^{\text {fuel }}\left(\mathrm{N}_{2}\right)=10 \%$} & 0.833 & 1 & $0.1 \%$ \\
\hline & 0.740 & 5 & $0.7 \%$ \\
\hline & 0.666 & -9 & $-1.4 \%$ \\
\hline $\mathrm{CH}_{4} / \mathrm{N}_{2}$ & 0.952 & -5 & $-0.5 \%$ \\
\hline \multirow[t]{3}{*}{$X^{\text {fuel }}\left(\mathrm{N}_{2}\right)=20 \%$} & 0.833 & -7 & $-0.8 \%$ \\
\hline & 0.740 & -2 & $-0.2 \%$ \\
\hline & 0.666 & -13 & $-1.9 \%$ \\
\hline $\mathrm{CH}_{4} / \mathrm{CO}_{2}$ & 0.952 & -17 & $-1.7 \%$ \\
\hline \multirow[t]{3}{*}{$X^{\text {fuel }}\left(\mathrm{CO}_{2}\right)=10 \%$} & 0.833 & -15 & $-1.8 \%$ \\
\hline & 0.740 & -8 & $-1.1 \%$ \\
\hline & 0.666 & -19 & $-2.9 \%$ \\
\hline $\mathrm{CH}_{4} / \mathrm{CO}_{2}$ & 0.952 & -99 & $-10.4 \%$ \\
\hline \multirow{3}{*}{$X^{\text {fuel }}\left(\mathrm{CO}_{2}\right)=50 \%$} & 0.833 & -80 & $-9.6 \%$ \\
\hline & 0.740 & -63 & $-8.5 \%$ \\
\hline & 0.666 & -60 & $-9.0 \%$ \\
\hline $\mathrm{CH}_{4} / \mathrm{H}_{2}$ & 0.941 & -15 & $-1.6 \%$ \\
\hline \multirow[t]{3}{*}{$X^{\text {fuel }}\left(\mathrm{H}_{2}\right)=20 \%$} & 0.823 & -6 & $-0.7 \%$ \\
\hline & 0.731 & 0 & $0.0 \%$ \\
\hline & 0.658 & -14 & $-2.1 \%$ \\
\hline $\mathrm{CH}_{4} / \mathrm{C}_{3} \mathrm{H}_{8}$ & 0.951 & 32 & $3.3 \%$ \\
\hline \multirow[t]{3}{*}{$X^{\text {fuel }}\left(\mathrm{C}_{3} \mathrm{H}_{8}\right)=5 \%$} & 0.832 & 19 & $2.2 \%$ \\
\hline & 0.739 & 20 & $2.8 \%$ \\
\hline & 0.665 & 7 & $1.1 \%$ \\
\hline
\end{tabular}

Equivalence ratio sensing is performed when the $\mathrm{OH}^{*}$ signal is well stabilized and each measurement is repeated five times to get an average value and determine a standard deviation. With a record time of one second of the photomulitplier signal, the standard deviation of the deduced equivalence ratio $\phi^{\prime}$ is lower than 0.001 . The absolute and relative bias errors of $\phi^{\prime}$ are listed in the third and fourth columns in Table 1. The absolute bias error $\left|\phi^{\prime}-\phi\right|$ remains below 0.01 for operation with pure methane or with $\mathrm{N}_{2}$ dilution up to 20 vol.\% This bias error slightly increases to 0.02 with 10 vol. $\% \mathrm{CO}_{2}$ or 20 vol. $\% \mathrm{H}_{2}$ in the fuel blend. However, for unpurified biogas with $50 \mathrm{vol} \% \mathrm{CO}_{2}$, the equivalence ratio becomes largely underestimated with $\left|\phi^{\prime}-\phi\right|$ up to 0.1 , making the results unusable for control purpose. With 5 vol.\%

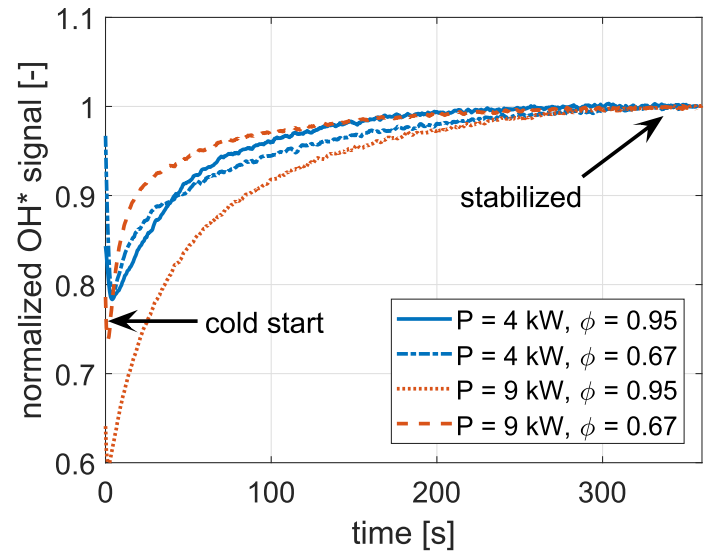

Fig. 8. Evolution of the $\mathrm{OH}^{*}$ signal measured with a photomultiplier tube over 6 min after a cold start of the burner. Intensity values are normalized by the steady state value. $\mathrm{CH}_{4}$-air mixture.

$\mathrm{C}_{3} \mathrm{H}_{8}$, the bias error is relatively large near stoichiometry with $\left|\phi^{\prime}-\phi\right| \sim 0.05$ but drops within the acceptable limit at leaner conditions. Since a domestic gas boiler operates typically around $\phi=0.8$ these bias errors remain acceptable.

\subsubsection{Impact of signal transient}

Another potential source of error is the transient response of the $\mathrm{OH}^{*}$ signal following a cold start of the burner after ignition or a sudden change of the flow operating conditions. In Fig. 8, the burner is ignited from cold conditions at different powers $P=4$ and $9 \mathrm{~kW}$ and different equivalence ratios $\phi=0.67$ and 0.95 . The $\mathrm{OH}^{*}$ signal is recorded over a period of $6 \mathrm{~min}$ and the signal intensities are normalized by their steady state value reached at the end. The $\mathrm{OH}^{*}$ intensity during the first instants is only $60-80 \%$ of the final value $I_{\max }$, and it takes $2-3 \mathrm{~min}$ to reach the stabilized final value. This transient response is attributed to the time necessary for the burner temperature to reach steady conditions.

The delayed response of the $\mathrm{OH}^{*}$ signal can also be observed after a sudden change of the flow operating conditions, as shown for example in Section 4.2. The equivalence ratio deduced from the $\mathrm{OH}^{*}$ signal is therefore incorrect during this transient period, which typically takes 10-20 s. The lag of the $\mathrm{OH}^{*}$ intensity response may be an issue if the characteristic time of the changes of the flow operating conditions is of the same order of magnitude or shorter than the time requested for signal stabilization. For example, the burner power is likely to be subject to frequent and drastic changes according to the demand for heating and hot water. This time lag needs therefore to be taken into account in the design of the future control algorithm in a real gas boiler. On the other hand, variations of the natural gas composition are relatively slow and mild, hence a certain time lag can be tolerated.

\section{Demonstrative equivalence ratio control loop}

\subsection{Control loop construction}

A demonstrative equivalence ratio control system is now developed. The system uses three Bronkhorst mass flow meters controlled by a LabVIEW program. They are used to change separately the mass flow

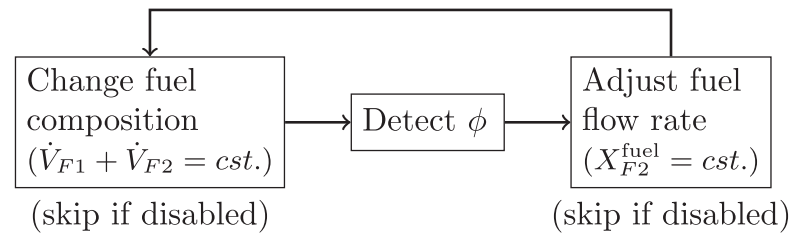

Fig. 9. Chart of the demonstrative equivalence ratio control loop. 


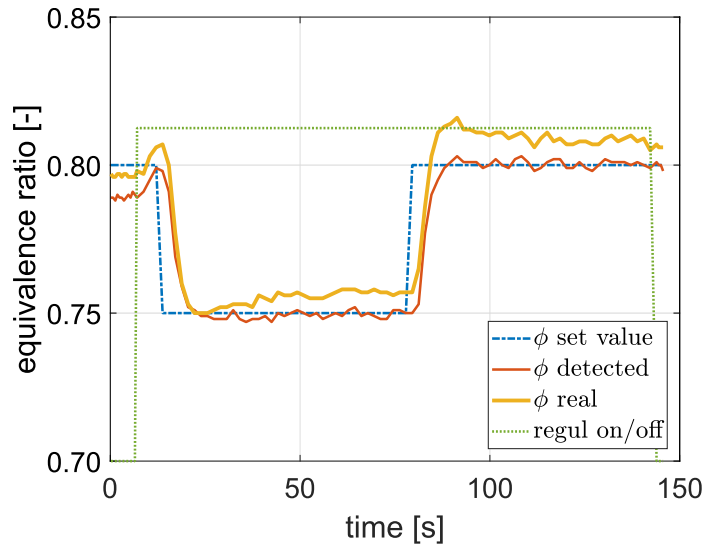

(a) $\mathrm{P}=4 \mathrm{~kW}$

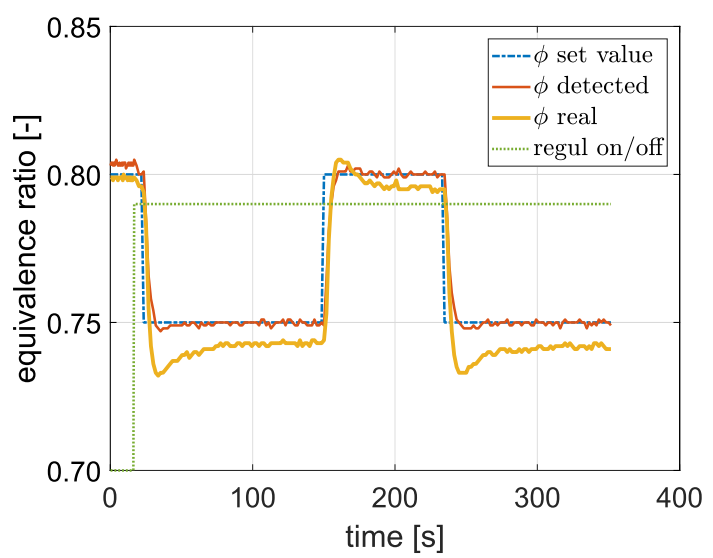

(b) $\mathrm{P}=7 \mathrm{~kW}$

Fig. 10. Tests of the control algorithm with methane/air mixtures at two different operating powers by changing the equivalence ratio set value. Automatic fuel flow rate regulation (green dotted line with arbitrary scale) is enabled from the beginning.

rates of air, methane and another secondary component $\left(\mathrm{N}_{2}, \mathrm{CO}_{2}, \mathrm{H}_{2}\right.$, $\mathrm{C}_{3} \mathrm{H}_{8}$ ). They are for convenience designated in the following by AIR, F1 $\left(\mathrm{CH}_{4}\right)$ and $\mathrm{F} 2\left(\mathrm{~N}_{2}, \mathrm{CO}_{2}, \mathrm{H}_{2}, \mathrm{C}_{3} \mathrm{H}_{8}\right)$ respectively.

Fig. 9 shows a simplified chart of the control loop. Each iteration of the loop is a three-step sequence:

- The first step is used to set the fuel composition according to the required secondary component molar fraction $X_{F 2}^{\text {fuel }}$ in the fuel blend. The global volumetric fuel flow rate $\left(\dot{V}_{F 1}+\dot{V}_{F 2}\right)$ is kept constant in this process. It mimics the situation of gas composition variations in a real gas boiler. The front panel gives a boolean signal which decides whether this step is executed or not. The set values for the flow meters F1 and F2 are calculated from the current value:

$\dot{V}_{F 1}=\left(\dot{V}_{F 1}^{0}+\dot{V}_{F 2}^{0}\right)\left(1-X_{F 2}^{\text {fuel }}\right)$

$\dot{V}_{F 2}=\left(\dot{V}_{F 1}^{0}+\dot{V}_{F 2}^{0}\right) X_{F 2}^{\text {fuel }}$

The superscript 0 denotes the initial flow rate given by the mass flow meters. After sending the set values to the mass flow rate controllers, the program is forced to wait two seconds to let the flow controllers to reach their desired values by changing the opening of their integrated valves.

- In the second step, the equivalence ratio is deduced from the $\mathrm{OH}^{*}$ signal according to the procedure described in Section 3.2. The air flow rate needed for this calculation is given by the air mass flow meter.

- The third step, executed when approved by a boolean signal from the front panel of the LabVIEW program, serves to regulate the global fuel flow rate, while keeping the fuel blend composition constant. The fuel flow rate is adjusted with the ratio of the detected equivalence ratio $\phi_{\text {detected }}$ to the set value $\phi_{\text {set }}$ as:

$$
\begin{aligned}
& \dot{V}_{F 1}=\dot{V}_{F 1}^{0} \frac{\phi_{\text {set }}}{\phi_{\text {detected }}} \\
& \dot{V}_{F 2}=\dot{V}_{F 2}^{0} \frac{\phi_{\text {set }}}{\phi_{\text {detected }}}
\end{aligned}
$$

A waiting time of one second is forced after sending the set points to the mass flow controllers.

It is worth mentioning that the control loop does not modify the air flow rate $\dot{V}_{A I R}$.

\subsection{Control algorithm validation}

\subsubsection{Change of equivalence ratio set value}

The performance of the control algorithm is first tested with pure methane by changing the set value of the equivalence ratio $\phi_{\text {set }}$ at two different flame powers $P=4$ and $7 \mathrm{~kW}$. Results are shown in Fig. 10 . The initial operating point of the burner is set to an equivalence ratio $\phi=0.80$. Automatic fuel flow rate regulation is started at the beginning and corresponds to the green dotted line with arbitrary scale. The set point of the equivalence ratio (blue line) is then switched back and forth between $\phi=0.80$ and $\phi=0.75$. The real equivalence ratio $\phi$ deduced from the mass flow meters is represented as a yellow line in Fig. 10 and serves as a reference which is not disclosed to the system. This quantity follows the set value in Fig. 10, with a small offset of $|\Delta \phi| \sim 0.01$

\subsubsection{Change of fuel composition}

Validation proceeds by changing the fuel composition. The following scenarios of binary fuel blends are considered. Some of them are chosen in accordance with reference gases used for gas boiler certification:

- $\mathrm{CH}_{4} / \mathrm{N}_{2}, X^{\text {fuel }}\left(\mathrm{N}_{2}\right)=14 \%$ (reference gas G25).

- $\mathrm{CH}_{4} / \mathrm{CO}_{2}, X^{\text {fuel }}\left(\mathrm{CO}_{2}\right)=10 \%$

- $\mathrm{CH}_{4} / \mathrm{C}_{3} \mathrm{H}_{8}, X^{\text {fuel }}\left(\mathrm{C}_{3} \mathrm{H}_{8}\right)=5 \%$ (typical in many natural gases).

- $\mathrm{CH}_{4} / \mathrm{C}_{3} \mathrm{H}_{8}, X^{\text {fuel }}\left(\mathrm{C}_{3} \mathrm{H}_{8}\right)=13 \%$ (reference gas $\mathrm{G} 21$ ).

- $\mathrm{CH}_{4} / \mathrm{H}_{2}, \mathrm{X}^{\text {fuel }}\left(\mathrm{H}_{2}\right)=23 \%$ (reference gas $\mathrm{G} 222$ ).

The secondary components are first added to and then removed from the methane injection to test the ability of the control algorithm to regulate the fuel flow rate in both ways.

A first example is given in Fig. 11 in which the fuel switches between pure methane and the reference gas G222 containing 23 vol.\%

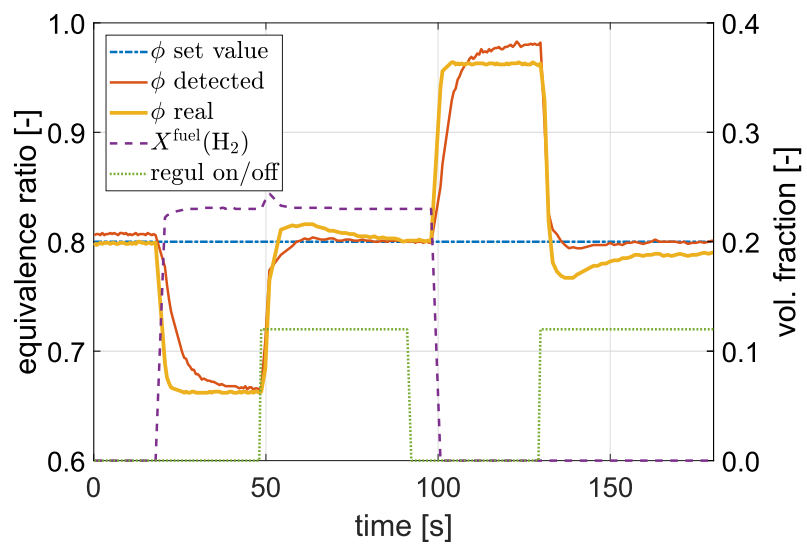

Fig. 11. Tests of the control system with fuel switching between pure methane and a $\mathrm{CH}_{4} / \mathrm{H}_{2}$ blend with $X^{\text {fuel }}\left(\mathrm{H}_{2}\right)=23 \%$. The signal for automatic fuel flow rate regulation (green dotted line with arbitrary scale) is sent manually after the detected equivalence ratio $\phi^{\prime}$ is stabilized. 


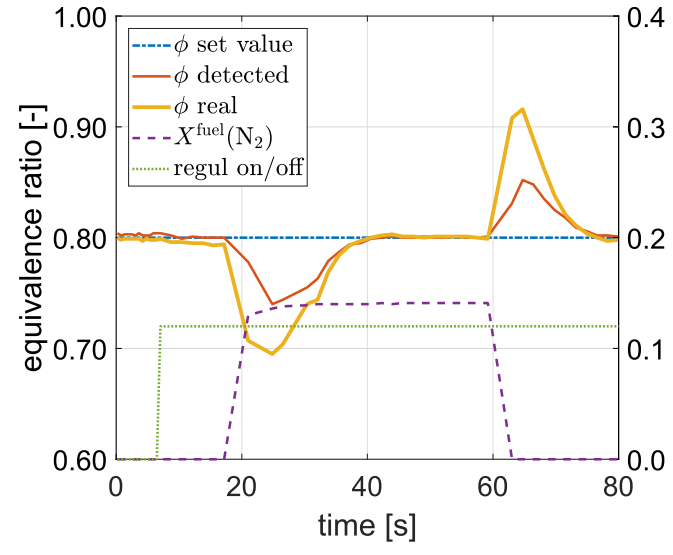

(a) $14 \%$ vol. $\mathrm{N}_{2}$

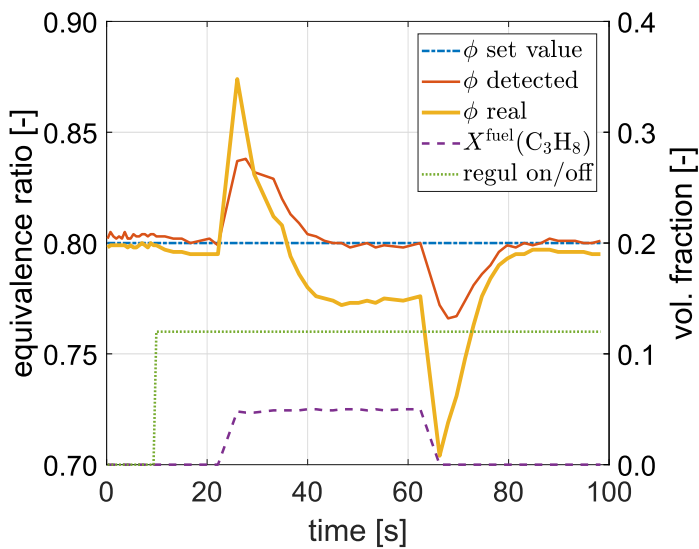

(c) $5 \%$ vol. $\mathrm{C}_{3} \mathrm{H}_{8}$

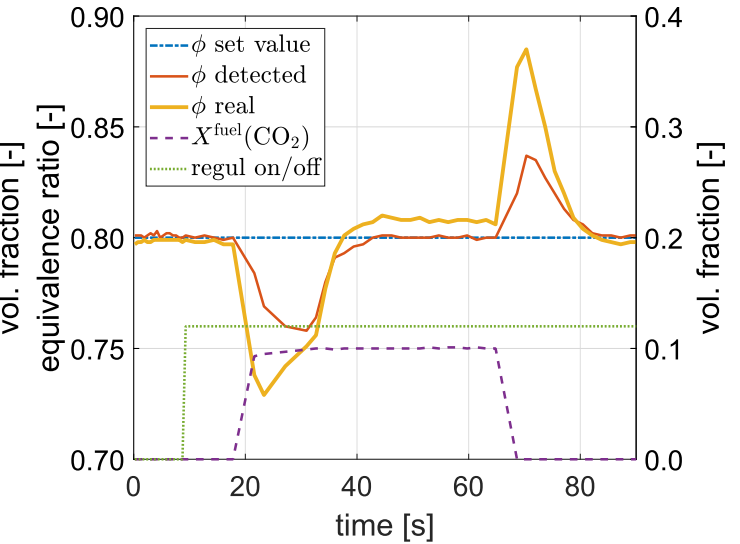

(b) $10 \%$ vol. $\mathrm{CO}_{2}$

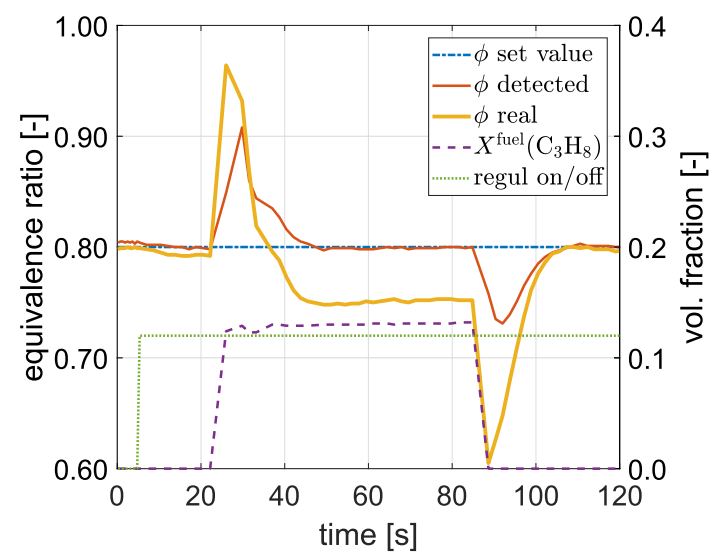

(d) $13 \%$ vol. $\mathrm{C}_{3} \mathrm{H}_{8}$

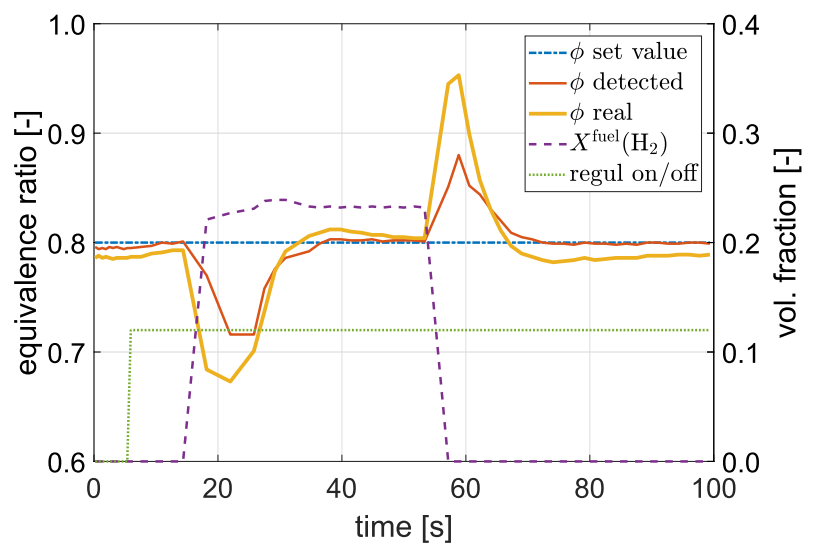

(e) $23 \%$ vol. $\mathrm{H}_{2}$

Fig. 12. Tests of the control system with binary fuel blends. The automatic fuel flow rate regulation is permanently enabled.

$\mathrm{H}_{2}$. Modifications of the fuel composition and automatic regulation are intentionally separated. The burner operates at $\phi=0.8$ at the beginning of the test and the automatic regulation (green dotted line) is disabled. At $t \sim 20 \mathrm{~s}, \mathrm{H}_{2}$ is injected to the fuel while the global fuel flow rate is kept constant. The real equivalence ratio is automatically affected and drops to $\phi \sim 0.66$. This drift is also detected by the control algorithm, but with a lag of about $25 \mathrm{~s}$ before reaching the correct value. The main contribution to this time lag is the lapse of time required by the burner to reach a stable temperature as discussed in Section 3.3. The regulation is then manually turned on at $t \sim 50 \mathrm{~s}$. The real equivalence ratio $\phi$ quickly goes back to the set value, despite a slight over-shoot during about $25 \mathrm{~s}$, corresponding again to the time for signal stabilization. When the secondary components are removed from the fuel in the second part of the test, the automatic regulation also successfully brings the equivalence ratio back to the set value.

Further validation tests are presented with other fuel compositions in Fig. 12. The automatic regulation is permanently enabled during these tests. The control system is found to react correctly to changes of the fuel composition for all cases tested and allows to regulate the equivalence ratio. The difference between the real equivalence ratio with respect to the set value remains generally below $|\Delta \phi|=0.01$ as shown by the results in Fig. 12a with 14 vol. $\% \mathrm{~N}_{2}$, in Fig. $12 \mathrm{~b}$ with 10 vol.\% $\mathrm{CO}_{2}$ and in Fig. $12 \mathrm{e}$ with 23 vol. $\% \mathrm{H}_{2}$. Only $\mathrm{C}_{3} \mathrm{H}_{8}$ enrichment causes relatively bigger deviations of $|\Delta \phi| \sim 0.03$ for $X^{\text {fuel }}\left(\mathrm{C}_{3} \mathrm{H}_{8}\right)=0.05$ in Fig. 12c and $|\Delta \phi| \sim 0.05$ for $X^{\text {fuel }}\left(\mathrm{C}_{3} \mathrm{H}_{8}\right)=0.13$ in Fig. 12d. The same differences are also expected for $\mathrm{C}_{2} \mathrm{H}_{6}$ enrichment which is not tested 
here. However, these differences still remain tolerable considering that the concentration of $\mathrm{C}_{3} \mathrm{H}_{8}$ in real natural gases remains generally lower than in the tested scenarios.

\subsubsection{Discussion}

The tests made revealed that the control strategy based on sensing the $\mathrm{OH}^{*}$ intensity combined with an information on the air flowrate is capable of regulating the equivalence ratio of unknown natural gas fuel blends with an excellent precision. The bias error remains below $|\Delta \phi|=0.01$ for pure methane and its blends with $\mathrm{N}_{2}, \mathrm{CO}_{2}$ and $\mathrm{H}_{2}$. Only $\mathrm{C}_{3} \mathrm{H}_{8}$ enriched fuel mixtures cause relatively larger differences with $|\Delta \phi| \sim 0.03$ for $X^{\text {fuel }}\left(\mathrm{C}_{3} \mathrm{H}_{8}\right)=0.05$ and $|\Delta \phi| \sim 0.05$ for $X^{\text {fuel }}\left(\mathrm{C}_{3} \mathrm{H}_{8}\right)=0.13$. These slight differences remain nevertheless tolerable for the targeted application in a domestic gas boiler.

The control loop developed in this work for a commercial burner used in real gas boilers, differs in some aspects from the work of Docquier et al. [26] conducted on a laboratory conical flame. In their work the equivalence ratio sensing is realized with a lookup table consisting of two intensity ratios $\mathrm{OH}^{*} / \mathrm{CH}^{*}$ and $\mathrm{CO}_{2}^{*} / \mathrm{CH}^{*}$, while in the present work the $\mathrm{OH}^{*}$ intensity from the photomultiplier tube scaled by the different air flow rates is preferred to detect the equivalence ratio. This sensing strategy allows the control system to be extended to a wider set of fuel scenarios. Tests with modifications of the equivalence ratio set value from methane/air mixtures and effects of $\mathrm{N}_{2}$ dilution were already carried out by Docquier et al. [26]. The validation is extended here to different flame powers and to a wider set of secondary components including $\mathrm{CO}_{2}, \mathrm{H}_{2}$ and $\mathrm{C}_{3} \mathrm{H}_{8}$ as well. On the other hand, no special attempt was made in the present work to optimize the PID controller of the different flow regulator devices, which is out of the scope of the present study. Also, the impact of the contamination of light-collecting equipments was not tested. Domestic gas boilers generally don't suffer from soot pollutions. It is nevertheless reminded that by selecting only one narrow spectral bandwidth relative to $\mathrm{OH}^{*}$ emission, the control strategy developed in the present work is indeed more vulnerable to signal intensity attenuation due to contamination obscuring the optical path.

Despite the success of the demonstrative control loop developed in this work in a laboratory framework, additional practical issues need to be addressed before envisaging applying this control technique to real gas boilers. For example, the delayed response of the $\mathrm{OH}^{*}$ signal cause difficulties to handle sudden changes of flame power. A preliminary rough adjustment with other techniques may be necessary before leaving fine regulations to the chemiluminescence-based control loop.

Another issue for an industrial application is that the optical access to the flame region is considerably restricted in a real boiler compared to the experiments made here with a burner taken out of the chamber. In the present laboratory setup, the photomultiplier tube is set perpendicular to the burner axis at a relatively large distance of about $50 \mathrm{~cm}$ from the burner surface. It therefore always safely collects the light emission from half of the small flames anchored on the cylindrical burner facing the sensor, despite variations of flame length with power and equivalence ratio. In a real gas boiler, on the other hand, the distance between the sensor and the flame region is likely to be reduced and the observation angle may largely be restricted by the solid components inside the combustion chamber, especially the heat exchanger set around the burner. In this case, changes of the flame length with power and equivalence ratio have to be considered. Flames may get in and out of the field of view depending on the operating conditions and the fraction of the flame emission collected by the sensor may not remain constant. In addition, as only the $\mathrm{OH}^{*}$ emission intensity is recorded, these modifications cannot be automatically compensated with a normalization technique using the ratio of two emission intensities. The same problem may arise if the technique is applied to unsteady flames when the flame enters or leaves the view frame covered by the sensor. It would then be important to verify whether monotonic calibration curves as in Fig. 6 could still be constructed in a real burner environment.

\section{Conclusion}

The present work proposes a new equivalence ratio sensing and regulation strategy for a laminar premixed burner used in domestic gas boilers.

Preliminary experiments first allowed to identify a reliable equivalence ratio indicator. The commonly used $\mathrm{CH}^{*} / \mathrm{OH}^{*}$ intensity ratio leads to large errors with $\mathrm{C}_{2} \mathrm{H}_{6}$ and $\mathrm{C}_{3} \mathrm{H}_{8}$ enriched methane blends, while use of the $\mathrm{C}_{2}^{*} / \mathrm{CH}^{*}$ intensity ratio does not cover a sufficiently wide operational range to safely determine the equivalence ratio. The $\mathrm{OH}^{*}$ signal has finally been selected because it barely changes with the fuel blend composition and features monotonic changes with $0.67 \leqslant \phi \leqslant 1.00$.

A demonstrative control loop has then been developed with LabVIEW. The equivalence ratio is determined during operation by measuring the $\mathrm{OH}^{*}$ intensity with a photomultiplier tube. An information on the air flow rate is also supplied to the control algorithm to account for power modulation. This control strategy has been tested by changing the equivalence ratio set value, the set power and by modifying the fuel composition with different fractions of $\mathrm{N}_{2}, \mathrm{CO}_{2}, \mathrm{H}_{2}$ and $\mathrm{C}_{3} \mathrm{H}_{8}$ mixed with methane. Regulation of the equivalence ratio of unknown natural gas fuel blends with an excellent precision has been proven for this fuel mixtures. Only $\mathrm{C}_{3} \mathrm{H}_{8}$ enriched fuel mixtures cause relatively larger, but tolerable bias errors on the detected equivalence ratio.

This control strategy validated in a laboratory framework on an industrial burner may easily be transferred to real domestic gas boilers as the information required on the air flow rate and $\mathrm{OH}^{*}$ intensity are both accessible in these systems. Nevertheless, potential difficulties that need be considered include the lag of the $\mathrm{OH}^{*}$ signal response due to thermal transients and the geometrical restriction of optical access to the flame region in the real system.

\section{Acknowledgments}

This work was supported by FUI (Fonds Unique Interministériel) [ZEM-R]. The authors also wish to thank David Charalampous for his help with spectrometry and Yannick Le Teno for the preparation of the experimental setup.

\section{References}

[1] M. Pöschl, S. Ward, P. Owende, Evaluation of energy efficiency of various biogas production and utilization pathways, Appl. Energy 87 (11) (2010) 3305-3321.

[2] T. Estermann, M. Newborough, M. Sterner, Power-to-gas systems for absorbing excess solar power in electricity distribution networks, Int. J. Hydrogen Energy 41 (32) (2016) 13950-13959.

[3] S. Lee, S.-M. Kum, C.-E. Lee, An experimental study of a cylindrical multi-hole premixed burner for the development of a condensing gas boiler, Energy 36 (7) (2011) 4150-4157.

[4] S. Lee, S.-M. Kum, C.-E. Lee, Performances of a heat exchanger and pilot boiler for the development of a condensing gas boiler, Energy 36 (7) (2011) 3945-3951.

[5] V. Dupont, M. Pourkashanian, A. Williams, R. Woolley, The reduction of NOx formation in natural gas burner flames, Fuel 72 (4) (1993) 497-503.

[6] H.R.N. Jones, The Application of Combustion Principles to Domestic Gas Burner Design, Taylor \& Francis, 1989.

[7] N. Docquier, S. Candel, Combustion control and sensors: a review, Prog. Energy Combust. Sci. 28 (2) (2002) 107-150.

[8] G. Tschulena, A. Lahrmann, Sensors applications, Sensors in Household Appliances vol. 5, John Wiley \& Sons, 2006.

[9] M. Kiefer, U. Maas, S. Park, X. Pian, G. Köllmann, G.O. Loohuis, D. Leerkes, H. Kalk, D. Markus, T. Langer, Combustion control based on flame ionization, in: 25th World Gas Conference, 04-08 June 2012, Kuala Lumpur, Malaysia.

[10] M. Näslund, Combustion control in domestic gas appliances - fuel gases containing hydrogen, Tech. rep., Danish Gas Technology Centre, 042014.

[11] B. Lewis, G. von Elbe, Chapter V - combustion waves in laminar flow, in: B. Lewis, G.V. Elbe (Eds.), Combustion, Flames and Explosions of Gases, Third ed., Academic Press, San Diego, 1987, pp. 215-417.

[12] Y. Ding, D. Durox, N. Darabiha, T. Schuller, Combustion state monitoring of premixed heating appliances with flame ionization current and chemiluminescence, Combust. Sci. Technol., doi:10.1080/00102202.2018.1472085.

[13] M. Karrer, Diagnostic des plasmas de combustion par sonde d'ionisation: application à l'étude de l'interaction flamme-paroi instationnaire, Ph.D. thesis, Chasseneuil-du-Poitou, Ecole nationale supérieure de mécanique et d'aéronautique, 
France, 2009.

[14] J.M. Rodrigues, Analyse de la répartition du potentiel et des charges dans une flamme polarisée. corrélation avec la distance d'extinction, Ph.D. thesis, Université de Rouen, 2005.

[15] V. Nori, J. Seitzman, Chemiluminescence measurements and modeling in syngas, methane and jet-a fueled combustors, in: AIAA-2007-0466, 45th AIAA Aerospace Sciences Meeting and Exhibit, Reno, NV, January, 2007, pp. 8-11.

[16] L. Zimmer, S. Tachibana, T. Yamamoto, Y. Kurosawa, K. Suzuki, Evaluation of chemiluminescence as sensor for lean premixed combustion, in: 4th Symposium on Smart Control of Turbulence, March 2-4, 2003, Tokyo, Japan.

[17] Y. Hardalupas, M. Orain, C.S. Panoutsos, A. Taylor, J. Olofsson, H. Seyfried, M. Richter, J. Hult, M. Aldén, F. Hermann, J. Klingmann, Chemiluminescence sensor for local equivalence ratio of reacting mixtures of fuel and air (FLAMESEEK), Appl. Therm. Eng. 24 (11-12) (2004) 1619-1632.

[18] J. Ballester, T. García-Armingol, Diagnostic techniques for the monitoring and control of practical flames, Prog. Energy Combust. Sci. 36 (4) (2010) 375-411.

[19] C. Hu, Y. Gong, Q. Guo, Y. Wang, G. Yu, Experimental study on the spectroscopy of opposed impinging diesel flames based on a bench-scale gasifier, Energy Fuels 31 (4) (2017) 4469-4478.

[20] C. Hu, Y. Gong, Q. Guo, L. He, G. Yu, Investigations of ch chemiluminescence and blackbody radiation in opposed impinging coal-water slurry flames based on an entrained-flow gasifier, Fuel 211 (2018) 688-696.

[21] J. Kojima, Y. Ikeda, T. Nakajima, Spatially resolved measurement of $\mathrm{OH}^{*}, \mathrm{CH}^{*}$, and $\mathrm{C}_{2}^{*}$ chemiluminescence in the reaction zone of laminar methane/air premixed flames, Proc. Combust. Inst. 28 (2) (2000) 1757-1764.

[22] B. Higgins, M. McQuay, F. Lacas, J.-C. Rolon, N. Darabiha, S. Candel, Systematic measurements of $\mathrm{OH}$ chemiluminescence for fuel-lean, high-pressure, premixed, laminar flames, Fuel 80 (1) (2001) 67-74.

[23] B. Higgins, M. McQuay, F. Lacas, S. Candel, An experimental study on the effect of pressure and strain rate on $\mathrm{CH}^{*}$ chemiluminescence of premixed fuel-lean methane/ air flames, Fuel 80 (11) (2001) 1583-1591.

[24] Y. Hardalupas, M. Orain, Local measurements of the time-dependent heat release rate and equivalence ratio using chemiluminescent emission from a flame, Combust. Flame 139 (3) (2004) 188-207.

[25] C. Panoutsos, Y. Hardalupas, A. Taylor, Numerical evaluation of equivalence ratio measurement using $\mathrm{OH}^{*}$ and $\mathrm{CH}^{*}$ chemiluminescence in premixed and non-premixed methane-air flames, Combust. Flame 156 (2) (2009) 273-291.

[26] N. Docquier, F. Lacas, S. Candel, Closed-loop equivalence ratio control of premixed combustors using spectrally resolved chemiluminescence measurements, Proc Combust. Inst. 29 (1) (2002) 139-145.

[27] M. Adelt, M. Hoppe, M. Montero, G. Peureux, Report on gas composition range in Europe DB0.1, Tech. rep., INGAS, 2010.

[28] T. García-Armingol, J. Ballester, A. Smolarz, Chemiluminescence-based sensing of flame stoichiometry: influence of the measurement method, Measurement 46 (9) (2013) 3084-3097.

[29] Y. Ding, Use of flame chemiluminescence and ionization current for the combustion state monitoring of a domestic gas boiler, Ph.D. thesis, Université Paris-Saclay, 2018.

[30] J.-M. Samaniego, F. Egolfopoulos, C. Bowman, $\mathrm{CO}_{2}^{*}$ chemiluminescence in premixed flames, Combust. Sci. Technol. 109 (1-6) (1995) 183-203.

[31] S. Schiebahn, T. Grube, M. Robinius, V. Tietze, B. Kumar, D. Stolten, Power to gas: technological overview, systems analysis and economic assessment for a case study in Germany, Int. J. Hydrogen Energy 40 (12) (2015) 4285-4294. 